\title{
Centros comerciales de la Ciudad de México: el ascenso de los negocios inmobiliarios orientados al consumo ${ }^{1}$
}

José Gasca-Zamora. Universidad Nacional Autónoma de México, Ciudad de México, México.

RESUMEN | El centro comercial es uno de los principales hitos en las grandes ciudades contemporáneas. Su rápido crecimiento y difusión en los últimos lustros replantean nuevas formas en la edificación y organización espacial de los lugares orientados a la distribución y el consumo de bienes y servicios. La Ciudad de México ha registrado desde los años noventa un auge sin precedentes en la captación de inversiones inmobiliarias, entre ellas las materializadas en megaproyectos comerciales. En este trabajo se aborda el proceso de expansión de los centros comerciales desde tres vertientes: primero, como parte del despliegue de los circuitos de capital colocados en grandes proyectos inmobiliarios de la ciudad; segundo, como resultado de la expansión de nuevas escalas y formas de consumo, promovidas por corporativos locales y globales de distribución minorista; finalmente, como dispositivos que articulan nuevas formas de producción y reestructuración del espacio urbano, especialmente a partir de las subcentralidades que promueven.

PALABRAS CLAVE | mercado inmobiliario, consumo, economía urbana.

ABSTRACT | The shopping mall is one of the major landmarks in contemporary cities. Its rapid expansion and diffusion suggests the reconsideration of new forms of building and spatial organization of places oriented to the distribution and consumption of goods and services. Mexico City has registered since the nineties an unprecedented boom in attracting investment in various segments of real estate, one of which is the retail megaprojects. This paper analyzes the process of expansion of shopping centers from three aspects. First, as part of the deployment of circuits of capital placed in large real estate projects in the city; second, as the result of the expansion of new forms and scales of consumption promoted by local and global corporations of retail distribution. Finally, as devices that articulate new forms of production of urban space, especially from the sub-centers they promote.

KEYWORDS | real estate market, consumption, urban economy.

Recibido el 29 de agosto de 2016, aprobado el 16 de diciembre de 2016

E-mail: jgasca@unam.mx

1 Este trabajo es resultado del proyecto: “Dinámicas socioeconómicas y espaciales de los grandes proyectos inmobiliarios residenciales y de servicios en ciudades de México", realizado bajo el Programa de Apoyo a Proyectos de Investigación e Innovación Tecnológica (PAPIIT-IN3027I7), auspiciado por la Dirección General de Asuntos del Personal Académico de la Universidad Nacional Autónoma de México (UNAM). El autor agradece el apoyo brindado por Enrique Castro Martínez en la elaboración de la cartografía y el procesamiento de datos estadísticos. 


\section{Introducción}

La aparición de nuevas formas y medios de consumo en la sociedad contemporánea va redefiniendo nuestra relación no solo con los objetos que adquirimos, sino también con los lugares de que disponemos para acceder a los mismos. Bajo el advenimiento de lo que se ha denominado la sociedad de los consumidores y la difusión de una cultura de consumo de rasgos globales (Bauman, 2007), ingresamos a una etapa donde los espacios asumen nuevos significados, transformando con ello una parte sustantiva de las relaciones sociales y la vida cotidiana de las personas. La expansión de cadenas globales de empresas comerciales como supermercados, tiendas departamentales y especializadas, así como franquicias y otros esquemas de distribución, ha facilitado el posicionamiento de productos que se vuelven iconos mundiales. Para ello se han implementado modelos de circulación de mercancías a gran escala a través de equipamientos físicos y mediante soportes virtuales, entre estos los sistemas de crédito y las transacciones vía internet (Ritzer, 2006). Ello ocurre en un contexto donde los consumidores se vuelven dominantes y los productores tienen que adaptarse a ellos; donde las mercancías adquieren una fuerte carga simbólica y devienen efímeras, y donde el consumo se hace menos funcional y más estético (Lash \& Urry, 1998). En este contexto los centros comerciales (cc) adquieren una mayor presencia, pues constituyen dispositivos para acelerar y maximizar la distribución de bienes, integran vehículos para canalizar las preferencias volátiles de consumo y se convierten en escenarios donde se reinventan permanentemente los productos y actividades de ocio y entretenimiento.

Los CC se distinguen por sus edificaciones construidas sobre grandes superficies donde se incorporan empresas minoristas que ofertan mercancías y servicios básicos y especializados, ${ }^{2}$ lo que permite el desarrollo de conjuntos multifuncionales donde se lleva a cabo un flujo diversificado, integrado y continuo de consumo. Se tienen registros de que el primer cc bajo techo apareció en 1956 en Minnesota, Estados Unidos de América (EUA); desde entonces han sido adoptados como parte de la cultura del consumo contemporáneo, incrustándose en la trama urbana de un gran número de metrópolis y grandes ciudades alrededor del mundo, con diferentes ritmos e intensidades. ${ }^{3}$ En América Latina, Brasil y México atestiguaron su nacimiento durante la década de los sesenta, mientras que en otros países de la región la apertura de cc se reporta en los ochenta. En la Ciudad de México, durante sus primeras dos décadas tuvieron un moderado crecimiento y aparecieron como enclaves inusuales en el paisaje urbano. Sin embargo, desde mediados de la década

2 Otros términos utilizados para referirse a estos lugares son los de plaza comercial, conjunto comercial y complejo comercial, mientras que en la literatura anglófona se reconocen bajo conceptos como shopping centers o shopping malls. En este trabajo únicamente los denominaremos centros comerciales, considerando que no son equipamientos homogéneos y que presentan distintas modalidades, escalas y funciones.

3 Molinillo (2002) desarrolla un exhaustivo análisis de las múltiples formas que han adquirido las unidades y concentraciones comerciales urbanas. Para el caso de los centros comerciales, considera que se distinguen por su carácter planificado, por estar construidos arquitectónicamente bajo una forma unificada, generalmente bajo techo, y con su operación integrada por una gerencia única. 
de los noventa han registrado un acelerado crecimiento y amplia dispersión en el tejido urbano, configurando un fenómeno de dimensiones metropolitanas.

En este trabajo se explican desde tres vertientes los factores que impulsaron el crecimiento y la difusión espacial de los cc en la Zona Metropolitana del Valle de México (zMvm): ${ }^{4}$ primero, como parte de la expansión de capital inmobiliario de la ciudad; segundo, resultado de nuevas escalas y formas de consumo promovidas por corporativos locales y globales de distribución minorista finalmente, como dispositivos que articulan nuevas formas de producción y reestructuración del espacio urbano. El artículo se organiza en tres apartados. En el primero se consideran referentes del estado del conocimiento respecto de los CC y su participación en el contexto latinoamericano. En el segundo se analiza la contribución de los actores asociados a la edificación y operación de los cc. En el tercero se explica su proceso de crecimiento y difusión espacial y se analizan algunos cambios que promueven en el espacio urbano.

\section{Estado del conocimiento}

Los CC han sido analizados con diferentes enfoques. Uno de ellos destaca su papel en los procesos de consumo partiendo del análisis de los sistemas de significados y representaciones sociales. Así, por ejemplo, Escudero (2008) considera que los CC recrean ambientes a través de elementos visuales e iconográficos para persuadir los deseos de consumir. Para el autor, tales representaciones dan lugar a una diversidad de productos, usos y readaptaciones de los espacios donde tienen lugar, en los cuales confluyen gustos, prácticas y eventos que los llevan a erigirse como lugares emblemáticos de la posmodernidad. En México, autores como Caprón y Sabatier (2007), Cornejo (2007), López (1999), Monnet (1996), entre otros, han incursionado en una línea similar al reconocer cómo los cc favorecen formas emergentes de sociabilidad, al igual que lugares que suscitan percepciones e imaginarios para dotar de nuevos sentidos a los usos del espacio y el tiempo. Una lectura alternativa da cuenta de cómo los Cc refuerzan la segregación urbana, proceso derivado de la edificación de recintos fortificados, la formación de enclaves de consumo y la sustitución de espacios públicos (López, 2006; Medina, 1998; Salcedo-Hansen, 2003).

Estas perspectivas críticas de la cultura contemporánea del consumo resultan atractivas. Sin embargo, este trabajo explora una veta distinta. Se trata de analizar el papel de las empresas del sector inmobiliario y comercial, agentes clave en la edificación de estos equipamientos, y el ascenso de nuevas formas y escalas en la

4 La zмVM integra el territorio que corresponde a la demarcación histórica del Distrito Federal, capital del país, que recientemente cambió su denominación a Ciudad de México (CDMx). A dicha demarcación se encuentran vinculados física y funcionalmente 16 delegaciones de la CDMX, 59 municipios del estado de México y uno de Hidalgo. En este trabajo se utiliza indistintamente Ciudad de México y zмvм. De acuerdo con los datos del Catálogo del Sistema Urbano Nacional, esta metrópoli registró una población de 20,2 millones de habitantes. Véase Consejo Nacional de Población (Conapo)-Secretaría de Desarrollo Social (Sedesol)-Secretaría de Gobernación (Segob), Catálogo Sistema Urbano Nacional 2012 (en línea), http://www.conapo.gob.mx/en/CONAPO/ Catalogo_Sistema_Urbano_Nacional_2012. 
distribución y el consumo. Interesa conocer cómo los cc contribuyen a movilizar grandes flujos de capital y su papel en la producción y reestructuración espacial urbana. Esta perspectiva, si bien no es del todo nueva, en México ha recibido poca atención. Así, Valenzuela (2013) sitúa el cc como parte de los grandes proyectos corporativos articulados al capital global, como en el caso paradigmático del complejo de Santa Fe en la Ciudad de México. Por su parte, Vázquez (2007) arriba a resultados similares a partir del caso Angelópolis en el estado de Puebla. Un trabajo relevante es desarrollado por Pradilla, Márquez, Carreón y Fonseca (2008), que al analizar el proceso de expansión de CC en la Ciudad de México destacan, entre otros aspectos, su contribución a la consolidación de áreas de actividad terciaria. En un sentido similar, Paquette (2007) enfatiza cómo los Cc han favorecido en la Ciudad de México la emergencia y consolidación de subcentros, resaltando su papel estructurador y regenerador del tejido urbano.

En América Latina, la literatura sobre el tema ha documentado distintos procesos inducidos por los cc en la escala nacional e intraurbana. Pintaudi y Frúgol (1992) indagan en Brasil las condicionantes socioeconómicas del surgimiento de cC y sus estrategias de localización en distintas ciudades; lo hacen especialmente a partir de su auge, registrado durante la década de los ochenta, asociado a las estrategias del capital financiero-inmobiliario, la dinámica de grandes mercados de consumidores y la emergencia de segmentos de alto poder adquisitivo concentrados en las principales metrópolis de dicho país. En un sentido similar, Amaya (2009) analiza el rol de los Cc en las principales aglomeraciones urbanas de Venezuela, destacando la tendencia hacia su concentración en las ciudades de mayor jerarquía y su propensión a localizarse en las áreas de sectores socioeconómicos de ingresos medios y altos, siguiendo el proceso de fragmentación social de las ciudades estudiadas.

En Argentina, Vecslir y Cicolella (2011) analizan los cc en la Región Metropolitana de Buenos Aires como parte del proceso de difusión territorial de las actividades terciarias en las dos últimas décadas y su relación con las diferentes modalidades de reestructuración de las centralidades y subcentralidades metropolitanas, destacando su integración en las tendencias de consolidación de morfologías y localizaciones tradicionales y la red emergente de distritos terciarios. Estudios recientes en Chile, como el realizado por De Simone (2015), abordan el protagonismo que los malls han adquirido en el mercado de suelos y su importante rol en el proceso de construcción social y estructuración urbana. Considerando su evolución desde sus orígenes y los procesos de transformación y mutación que se registran actualmente en Santiago de Chile, la autora destaca cómo tales centros comerciales responden a una expresión física de la sensibilidad posmoderna, tanto en la configuración territorial de las periferias metropolitanas como en la privatización del espacio público. Otro trabajo destacable es el de Dávila (2016), quien, desde una perspectiva latinoamericana, analiza cómo el boom de los shopping malls en diferentes ciudades representa una de las claves para entender la revaloración del suelo urbano y el crecimiento urbano a partir de la conjugación de un nuevo régimen financiero y políticas urbanas neoliberales.

En este trabajo se considera que los cc forman parte de las actividades comerciales emergentes que se distribuyeron progresivamente hacia áreas suburbanas 
y periféricas de la ciudad, lo cual refleja el proceso de disociación que diferentes segmentos de la economía comenzaron a tener con respecto al sector tradicional de negocios, generalmente el centro histórico de las ciudades, donde se situó el núcleo más importante de actividad comercial. En segundo lugar, se plantea que el fenómeno anterior está vinculado a la difusión urbana y el crecimiento de nuevas zonas sociorresidenciales de nivel medio que demandaron equipamientos para cubrir sus necesidades de bienes y servicios. Esto habría marcado una ruptura respecto a los segmentos precedentes del comercio popular, los cuales, en el caso de la Ciudad de México, hasta hace pocos ańos se ubicaban como los canales más representativos de la distribución de bienes. La transición progresiva de sistemas tradicionales a formatos empresariales de diversas escalas se observa en la amplia colonización que recientemente presentan hipermercados, clubes de precios, franquicias, almacenes especializados, tiendas de conveniencia, entre otros. Finalmente, se postula que la edificación de CC representa una de las modalidades más importantes de la financiarización de la edificación urbana a partir de su inserción en el mercado inmobiliario. Varias ciudades mexicanas registran desde los ańos noventa un auge sin precedentes en la captación de inversiones en conjuntos residenciales; también en edificios del sector corporativo y de oficinas, complejos de usos mixtos, distritos terciarios, hoteles y segundas residencias en zonas costeras y centros turísticos y, obviamente, en los destinados a megaproyectos comerciales.

Los CC son destino de cuantiosas inversiones privadas nacionales y globales atraídas por la revaloración del suelo urbano y las altas rentas que generan, fenómeno que se favorece en un contexto de políticas urbanas neoliberales que han impulsado acciones de promoción para atraer inversiones foráneas, y de nuevos códigos de desregulación, redensificación y recalificación del suelo orientadas a la renovación del ambiente construido, la revitalización urbana y la reactivación económica.

Los CC mexicanos tienen actualmente una presencia sobresaliente en el contexto latinoamericano tanto en número como en superficie de venta. De acuerdo con el International Council of Shopping Centers (ICSC, 2015), en el año 2014 México ocupó el primer lugar en América Latina, con 584 unidades; le siguen Brasil con 511, Colombia con 196 y Argentina con 114 (tabla 1). México también cuenta con más superficie rentable al sumar 16,2 millones de metros cuadrados; y después de Chile, tiene el ratio comercial urbano más alto en este segmento, equivalente a 16,9 metros cuadrados por cada 100 habitantes (ICSC, 2015). El crecimiento diferenciado de $\mathrm{CC}$ en algunos países representativos de América Latina sugiere una relación directa respecto a la población urbana absoluta y relativa de cada país. Sin embargo, el hecho de que México supere a Brasil en número de cc, y Chile a México en términos de ratio comercial, evidencia que se trata de un fenómeno más complejo. Existen indicios para pensar que la difusión del modelo de CC en esta escala estaría relacionada principalmente a la estructura del sistema urbano y la presencia de segmentos sociorresidenciales medios y altos en las ciudades.

Asimismo, se advierte que las metrópolis y grandes ciudades albergan el mayor número de cc y superficie rentable, fenómeno atribuible a la presencia de mercados más densos y zonas con sectores de mayor ingreso. Esto se observa en Brasil, Argentina, Chile, Venezuela y Perú, donde metrópolis como São Paulo, Buenos 
Aires, Santiago, Caracas y Lima han registrado mayor crecimiento del número de CC en comparación con otras ciudades en estos mismos países. Esta idea también se confirma para México, donde a pesar de que se reconoce la presencia de 59 zonas metropolitanas, solo las tres más grandes (México, Guadalajara y Monterrey) concentran alrededor de $70 \%$ de los CC y de superficie rentable. La ZMvM constituye un caso excepcional, pues con poco más de 20 millones de habitantes alojaba a mediados del año 2016 más de 200 cc, equivalentes a casi una tercera parte del total nacional.

TAbla I Centros comerciales de países seleccionados en América Latina, 2014 y estimados al año 2025

\begin{tabular}{|c|c|c|c|c|c|c|}
\hline \multirow[t]{2}{*}{ PAÍS } & \multicolumn{2}{|c|}{$\begin{array}{l}\text { NÚMERO DE CENTROS } \\
\text { COMERCIALES }\end{array}$} & \multicolumn{2}{|c|}{$\begin{array}{l}\text { SUPERFICIE DE VENTA } \\
\text { (MILLONES DE } \mathbf{M}^{2} \text { ) }\end{array}$} & \multicolumn{2}{|c|}{$\begin{array}{c}\text { RATIO COMERCIAL } \\
\text { URBANO } \\
\left(\mathrm{M}^{2} \text { POR CADA IOO HAB. }\right)\end{array}$} \\
\hline & 2014 & 2025 & 2014 & 2025 & 2014 & 2025 \\
\hline México & 584 & 760 & 16,9 & 23,3 & 16,9 & 22,0 \\
\hline Brasil & 511 & 700 & 13,5 & 22,8 & 7,8 & 12,0 \\
\hline Colombia & 196 & 339 & 4,2 & 8,3 & 10,8 & 18,0 \\
\hline Argentina & 114 & 178 & 2,1 & 4,3 & 5,4 & 10,0 \\
\hline Chile & 79 & 320 & 3,5 & 6,5 & 22,2 & 22,0 \\
\hline Perú & 71 & 90 & 9,2 & 3,8 & 9,2 & 25,0 \\
\hline
\end{tabular}

FUENTE $\operatorname{ICSC}(2015,5)$

\section{Convergencia del capital financiero, inmobiliario y comercial}

La producción de Cc implica un complejo proceso que va desde la adquisición de extensas superficies de suelo, al diseño y la gestión de grandes equipamientos y la coordinación de numerosas empresas y usuarios, por lo que representa un segmento donde solo intervienen firmas con importantes capacidades financieras, empresariales y logísticas. Existen tres actores que desempeńan roles complementarios en este proceso: las empresas inversionistas, que aportan los fondos de capital para la adquisición de suelo y su edificación; luego los desarrolladores inmobiliarios, que comprenden firmas que participan en el diseño, construcción y la promoción de locales para atraer negocios: ambos agentes promueven el cc básicamente como un negocio inmobiliario; finalmente, en un segundo momento se integran las unidades minoristas, que ofertan productos y servicios.

Los primeros cc que surgieron en la Ciudad de México fueron resultado de la asociación entre tiendas departamentales y desarrolladores inmobiliarios nacionales. Las primeras, que dominaban algunos nichos de mercado de la ciudad, incursionaron en la construcción de cc como estrategia para captar mayores cuotas de consumidores, promoviendo alrededor de su propia edificación la apertura de unidades complementarias de distribución de productos, servicios y entretenimiento. Este fue un principio para el diseńo del cc, donde la tienda ancla departamental representaba 
su eje articulador. Alianzas entre tiendas departamentales y desarrolladores inmobiliarios domésticos facilitaron la edificación de Plaza Universidad en 1969, primer CC en el país, resultado de la colaboración entre la empresa norteamericana Sears Roebuck $^{5}$ y la firma inmobiliaria Sordo Madaleno. Una operación similar sentó las bases para edificar Plaza Satélite en 1971, producto de la asociación de las tiendas departamentales Sears Roebuck, El Puerto de Liverpool y París Londres, con Sordo Madaleno. Estos esquemas de complementariedad entre capital comercial e inmobiliario se han mantenido a lo largo del tiempo, por ejemplo en la edificación del Centro Comercial Perisur, Galerías Insurgentes y Galerías Coapa, donde participó la tienda departamental El Puerto de Liverpool. Por su parte, la empresa El Palacio de Hierro participó en el financiamiento del Centro Comercial Coyoacán y, más recientemente, del cc ubicado en el desarrollo de usos mixtos Moliere Dos22. Estas fórmulas asociativas fueron imitadas en años posteriores por las empresas de supermercados de mayor presencia en el mercado mexicano, para edificar distintas modalidades de plazas y conjuntos comerciales.

El crecimiento reciente de CC forma parte de un nuevo régimen financiero en el direccionamiento de la producción urbana contemporánea en México y otros países latinoamericanos, sistema caracterizado por la participación, coalición y fusión de inversionistas, empresas inmobiliarias y actores financieros globales y nacionales, así como por la diversidad de fondos e instrumentos de inversión manejados por empresas, de los cuales pueden mencionarse pensiones, mutuos, seguros y hedge funds (De Mattos, 2007). En el caso de México también han proliferado instrumentos bursátiles que son colocados en distintas carteras de proyectos del mercado de bienes raíces; entre ellos, complejos residenciales, hoteles, edificios especializados en servicios médicos, parques industriales, infraestructuras carreteras y centros comerciales.

El mercado de megaproyectos destinados al consumo y comercio ha encontrado en México un campo fecundo para la captación de rentas urbanas. Cushman y Wakefield (2015), empresa encargada de monitorear precios de renta en áreas comerciales a nivel internacional, reportó que los tres cc en la Ciudad de México con mayores rentas por metro cuadrado mensuales son Antara Fashion Hall y Centro Comercial Perisur, con 80 dólares cada uno, seguidos por Centro Comercial Santa Fe, con 75 dólares, valores solo superados por la calle comercial de lujo Presidente Masaryk en la zona de Polanco y la calle peatonal Madero, ubicada en el centro histórico, que cotizaban cada una alrededor de 90 dólares por metro cuadrado. ${ }^{6}$

La tendencia hacia la captación de las elevadas rentas que generan los $\mathrm{Cc}$ ha desencadenado en los últimos ańos una mayor participación y competencia de inversionistas globales por colocar en distintas ciudades de México importantes flujos del capital requerido en este segmento, y otros relacionados con el mercado inmobiliario. Para tener una idea del tamaño de inversiones de empresas globales

5 Esta empresa departamental norteamericana se instaló en Ciudad de México en 1947. Grupo Carso adquirió parte de sus acciones en 1997 y en su totalidad en 2007, arrendando solo el nombre y el logotipo de la empresa.

6 Cifras correspondientes a septiembre de 2014. Si tomamos un tipo de cambio promedio de ese mismo ańo de 16,5 pesos por UsD, la renta por metro cuadrado de Antara y Perisur equivale a poco más de $\$ 1.150,00$ pesos. 
participantes, se estima que se colocaron aproximadamente 12 mil millones de dólares en los diferentes sectores de bienes raíces entre 1999 y 2010. Cabe destacar que, de estas inversiones, el $80 \%$ proviene de EuA y Canadá, el restante de algunos países de Asia y del Medio Oriente (Asociación Mexicana de Capital Privado [Amexcap], 2014).

Las distintas modalidades de finaciarización del sector inmobiliario en la edificación de CC se canalizan a través de diferentes fuentes. Desde finales de la década de los noventa del siglo xx y principios del xxI, se ha identificado esquemas que incluyen Consorcios de Inversión en Bienes Raíces (REIT, ${ }^{7}$ por sus siglas en inglés), proveedores de hipotecas y aseguradoras, así como diversas modalidades de fondos de capital privado. Entre estas se encuentran empresas como Kimco, PreI, GE Capital, ING, Hines, Black Creek, O'Connor y LaSalle Investment Management, MetLife y Walton Street (Lizan, 2014). Además de la participación de estas empresas globales, en años más recientes el finamiento de los Cc en México ha tenido un mayor dinamismo debido al surgimiento de varias modalidades de inversión bursátil, como los Certificados de Capital de Desarrollo (CKD) y los Fideicomisos de Inversión en Bienes Raíces (FIBRAs). Ambos han aportado nuevos recursos para expandir el margen de participación de capitales locales a partir de inversionistas de distinto tamaño.

Los CKD son instrumentos financieros mexicanos colocados por la Bolsa Mexicana de Valores (вмv), que pertenecen al Mercado de Capital de Desarrollo y sirven como vehículo para el financiamiento de actividades y proyectos de sectores con rendimientos a largo plazo, como infraestructura, minería y comunicaciones, entre otros. $^{8}$ Por su parte los FIBRAS se encargan de arrendar y administrar propiedades generadoras de rentas a través de un portafolio diversificado de bienes inmuebles donde participan desarrollos residenciales, hoteles, centros comerciales, complejos de oficinas, hospitales, entre otros. Los FIBRAs están inspirados en los CKD, cotizan en la BMV y son un instrumento abierto que conjuga esquemas heterogéneos donde participan inversionistas individuales, empresas desarrolladoras y operadores inmobiliarios. En México existen siete fibras, entre los cuales se encuentra Fibra Uno y Fibra Macquarie, con un portafolio de propiedades mixtas (oficinas, centros comerciales, terrenos industriales y hoteles); Fibra Hotel y Fibra Inn, especializados en hoteles; Fibra Shop, concentrado en centros comerciales; y Terrafina, orientado a propiedades industriales. Recientemente se creó Fibra Danhos, cuyo antecedente es la empresa desarrolladora homónima, y se encontraba en proceso de incorporación

7 Real Estate Investment Trust son sociedades de inversión propietarias de activos inmobiliarios cuyos ingresos proceden fundamentalmente de los alquileres de los mismos. Este esquema surgió en 1960 en EuA con el objetivo de que las inversiones a gran escala en bienes inmuebles fueran accesibles también a los pequeños inversionistas. La fórmula consistió en equiparar la inversión en productos inmobiliarios a la inversión en cualquier otra industria; es decir, a través de la compra de acciones. Por esta razón, aunque no están obligados, la mayor parte de estos grupos de inversión cotizan en el mercado bursátil.

8 Los CKD surgieron en 2009, junto con el cambio en la normatividad de la Comisión Nacional Sistema de Ahorro Para el Retiro, debido a la estrategia de ingresar al mercado financiero la gran masa monetaria manejada por las Administradoras de Fondos para el Retiro (Afores) y por la falta de liquidez por parte de las empresas de Desarrollo. De esta manera fungen alternativa los inversionistas mexicanos. 
en el mercado bursátil Fibra Sendero, ambos con trayectoria como desarrolladores de centros comerciales.

Las grandes empresas inversionistas internacionales y nacionales generalmente están asociadas a grupos de desarrolladores mexicanos y extranjeros, aunque algunos de estos también participan como arrendatarios, al ser poseedores de acciones compartidas con empresas inversionistas y comerciales, o bien participando en sus propias divisiones de empresas financieras. Por ello, es posible encontrar distintas modalidades de desarrolladores dentro del ámbito de construcción y operación de cC. En México, y particularmente en la ZMvM, la participación de desarrolladores y operadores en el mercado inmobiliario es diversificada, considerando la cantidad y tamaño de los proyectos donde vienen participando (tabla 2).

$\mathrm{Si}$ bien en varios casos los propios desarrolladores participan como inversionistas directos y/o en la administración de fondos bursátiles, algunos inversionistas presentan divisiones integradas por su propia empresa desarrolladora de inmuebles, tal y como se lleva a cabo por el Grupo Carso de Carlos Slim, quien controla uno de los holdings más diversificados en Latinoamérica al coordinar empresas del sector comercial minorista, industrial, energético y de construcción de infraestructura y equipamientos comerciales; su propia empresa desarrolladora, denominada Inmuebles Carso, se ha encargado de la edificación y administración de ocho cc en la Ciudad de México.

TABLA 2 Zona Metropolitana del Valle de México: principales desarrolladores inmobiliarios y empresas financiadoras de centros comerciales

\begin{tabular}{|c|c|c|}
\hline $\begin{array}{c}\text { EMPRESA } \\
\text { DESARROLLADORA }\end{array}$ & \multicolumn{2}{|c|}{ CENTROS COMERCIALES Y AÑO DE APERTURA } \\
\hline Grupo Frisa & $\begin{array}{l}\text { Multiplaza Valle Dorado (1974) } \\
\text { Multiplaza Alamedas (1976) } \\
\text { Multiplaza Bosques (1977) } \\
\text { Multiplaza San Juan (1980) } \\
\text { Multiplaza Aragón (1979) } \\
\text { Multiplaza Izcalli (1989) } \\
\text { Centro Comercial Plaza Jardines (1990) }\end{array}$ & $\begin{array}{l}\text { Multiplaza La Hacienda (1991) } \\
\text { Mundo E (1998) } \\
\text { Multiplaza Vergel (2000) } \\
\text { Magnocentro 26 (2001) } \\
\text { Multimart Baz (2001) } \\
\text { Multiplaza Arboledas (2006) } \\
\text { Multiplaza Ojo de Agua (2009) }\end{array}$ \\
\hline PLANI Grupo & Super Plaza Las Haciendas (2009) & Macroplaza Héroes de Tecámac (2009) \\
\hline ICON Commercial & $\begin{array}{l}\text { San Marcos Power Center (2005) } \\
\text { Coacalco Power Center (2007) }\end{array}$ & $\begin{array}{l}\text { Espacio Interlomas (2007) } \\
\text { Tecámac Power Center (2008) } \\
\text { Espacio Esmeralda (2008) }\end{array}$ \\
\hline $\begin{array}{l}\text { Mexico Retail } \\
\text { Properties }\end{array}$ & $\begin{array}{l}\text { El Cortijo Ixtapaluca (2006) } \\
\text { Patio Ayotla (2006) } \\
\text { Patio El Cortijo (2006) } \\
\text { Parques Polanco (2008) } \\
\text { Patio Chimalhuacán (2011) }\end{array}$ & $\begin{array}{l}\text { Gran Patio (2011) } \\
\text { Patio Santa Fe (2013) } \\
\text { Patio Universidad (2013) } \\
\text { Patio Clavería (2013) } \\
\text { Patio Santa Fe (2013) }\end{array}$ \\
\hline Grupo/Fibra Danhos & $\begin{array}{l}\text { Parque Duraznos }(2000) \\
\text { Parque Alameda }(2003) \\
\text { Plaza Magna }(2002) \\
\text { Parque Delta }(2005)\end{array}$ & $\begin{array}{l}\text { Parque Lindavista (2006) } \\
\text { Reforma } 222(2007) \\
\text { Parque Tezontle (2007) } \\
\text { Parque Toreo Central (2015) }\end{array}$ \\
\hline
\end{tabular}

(continúa) 
(continuación)

\begin{tabular}{|c|c|c|}
\hline $\begin{array}{c}\text { EMPRESA } \\
\text { DESARROLLADORA }\end{array}$ & \multicolumn{2}{|c|}{ CENTROS COMERCIALES Y AÑO DE APERTURA } \\
\hline E-Group/Fibra Uno & $\begin{array}{l}\text { Centro Comercial Interlomas (1991) } \\
\text { Vallejo } 2000 \text { (1994) } \\
\text { Vía Morelos (1997) } \\
\text { Plaza Legaria (1997) } \\
\text { Las Palomas (1998) } \\
\text { Multiplaza Tultitlán (2005) }\end{array}$ & $\begin{array}{l}\text { Centro Comercial Lago de Guadalupe } \\
\text { (2008) } \\
\text { Plaza Central (2010) } \\
\text { Terraza Pedregal (2010) } \\
\text { Samara Santa Fe (2011) } \\
\text { Pabellón Cuemanco (2013) } \\
\text { Pabellón Iztapalapa (2014) }\end{array}$ \\
\hline Grupo aCcion & Centro Comercial Insurgentes (1996) & Pabellón Altavista (1996) \\
\hline GICSA & $\begin{array}{l}\text { Paseo Arcos Bosques (2008) } \\
\text { Center Plazas (2006) } \\
\text { City Walk (2008) } \\
\end{array}$ & $\begin{array}{l}\text { Forum Buenavista (2008) } \\
\text { Paseo Interlomas (2009) }\end{array}$ \\
\hline Grupo АСвС & Plaza Las Flores (2004) & \\
\hline Grupo Acosta Verde & $\begin{array}{l}\text { Plaza Sendero Ixtapaluca (2005) } \\
\text { Plaza Sendero Ecatepec (2008) } \\
\end{array}$ & Gran Patio Valle de Chalco (2011) \\
\hline ZKC & $\begin{array}{l}\text { Plaza Cafetales (2015) } \\
\text { Plaza Picacho Ajusco (2015) } \\
\text { Plaza Eduardo Molina (2015) }\end{array}$ & $\begin{array}{l}\text { Plaza Copilco (2016) } \\
\text { Plaza Huipulco }(2016) \\
\text { Plaza Tenorios }(2016) \\
\end{array}$ \\
\hline Inmuebles Carso & $\begin{array}{l}\text { Pabellón Polanco (1990) } \\
\text { Plaza Loreto (1994) } \\
\text { Plaza Insurgentes (1996) } \\
\text { Plaza Inbursa Cuicuilco (1997) } \\
\text { Plaza Telmex Ciudad Jardín (2008) }\end{array}$ & $\begin{array}{l}\text { Mexipuerto Ciudad Azteca (2009) } \\
\text { Cetram El Rosario (2012) } \\
\text { Plaza Carso (2014) }\end{array}$ \\
\hline Sordo Madaleno & $\begin{array}{l}\text { Plaza Universidad }{ }^{/ 1}(1969) \\
\text { Plaza Satélite }^{/ 1}(1971) \\
\text { Centro Coyoacán }^{/ 2}(1982) \\
\end{array}$ & $\begin{array}{l}\text { Antara Polanco (2006) } \\
\text { Centro Comercial Lilas (1992) } \\
\text { Moliere Dos22/2 (1997) } \\
\end{array}$ \\
\hline Grupo GDI & $\begin{array}{l}\text { Gran Sur (1999) } \\
\text { Coacalco Power Center (2007) } \\
\text { Espacio Interlomas (2007) } \\
\text { Town Center El Rosario (2012) }\end{array}$ & $\begin{array}{l}\text { Espacio Esmeralda (2009) } \\
\text { Town Center Zumpango (2010) } \\
\text { Town Center Nicolás Romero (2013) } \\
\text { Cosmopol (2015) }\end{array}$ \\
\hline Grupo CAABSA & $\begin{array}{l}\text { Centro Comercial Santa Fe (1986) } \\
\text { Plaza Lindavista (1990) }\end{array}$ & Pabellón Bosques (1999) \\
\hline $\begin{array}{l}\text { Grupo Galerías/El } \\
\text { Puerto de Liverpool }\end{array}$ & $\begin{array}{l}\text { Centro Comercial Perisur (1979) } \\
\text { Galerías Coapa (1992) } \\
\text { Galerías Insurgentes (1992) }\end{array}$ & $\begin{array}{l}\text { Perinorte (1992) } \\
\text { Galerías Atizapán (2009) } \\
\text { Galerías Atizapán (2009) } \\
\end{array}$ \\
\hline Fibra Shop & $\begin{array}{l}\text { Puerta Texcoco }^{13}(2010) \\
\text { City Center Esmeralda }\end{array}$ & Urban Center Condesa $^{15}(2011)$ \\
\hline
\end{tabular}

NOTAS:

$\begin{array}{ll}/ \text { I } & \text { EN COPARTICIPACIÓN CON SEARS ROEBUCK } \\ / 2 & \text { EN COPARTICIPACIÓN CON EL PALACIO DE HIERRO } \\ / 3 & \text { DESARROLLADOR ORIGINAL GRUPO ACBC } \\ / 4 & \text { DESARROLLADOR ORIGINAL HINEST INTEREST } \\ 15 & \text { DESARROLLADOR ORIGINAL CENTRAL DE ARQUITECTURA } \\ \text { FUENTE } & \text { ELABORACIÓN PROPIA A PARTIR DE M.S.E MEDIOS DE COMUNICACIÓN (2OI5) Y PÁGINAS WEB } \\ & \text { DE LAS EMPRESAS DESARROLLADORAS }\end{array}$

Los Cc también funcionan como plataformas de distribución de cadenas locales y globales de retailers. Resultado de la globalización de firmas comerciales y de las políticas de liberalización a las inversiones directas que tuvieron lugar desde mediados de los ochenta, arribaron a México diversos corporativos de tiendas departamentales y supermercados. Sin embargo, en las últimas dos décadas el crecimiento y diversificación de los CC en México estuvieron ligados a la llegada de cadenas de retailers 
globales multimarca, los cuales han orientado las tendencias más importantes en la composición de negocios que operan en los cc. Las cadenas de tiendas departamentales, una buena parte de los grandes supermercados y la mayoría de retailers globales y nacionales en México suelen situarse principalmente en CC, donde captan sus mayores ingresos.

La utilización de la plataforma de distribución del cc por parte de estas empresas se basa en tres tipos de ventajas: las ventajas de operar bajo economías de aglomeración, las ventajas ligadas a la localización y aquellas vinculadas a la escala. En el primer caso, porque obtienen mayores ingresos por ventas cuando utilizan sistemas de proximidad espacial entre firmas, que si lo hicieran de manera aislada, generando complementariedades y un flujo integrado y continuo de consumo a través de una gama diversificada de oferta de mercancías, servicios básicos y amenidades en un solo lugar. Las segundas, porque al operar sobre ubicaciones estratégicas en distintas partes de la ciudad, adaptándose a contextos de consumidores de ingresos medios y altos, o bien situándose sobre vías primarias, corredores terciarios y terminales multimodales de transporte, aprovechan las ventajas de accesibilidad, lo que genera importantes fuerzas de atracción que permiten centralizar amplios aforos y posibilitan, en algunos casos, estructurar nuevas relaciones funcionales en la metrópoli a través de las subcentralidades que promueven. Las terceras porque registran mayores utilidades por unidad de producto al manejar grandes volúmenes, es decir, por la incorporación de economías de escala. Para ello aprovechan las ventajas derivadas de innovaciones logísticas, tecnológicas y mercadológicas, sobre todo considerando que buena parte de los productos que ofertan los grandes retailers proviene de complejas cadenas globales de distribución. Así, bajo este esquema, el cc es un lugar que asegura una elevada y más rápida circulación de mercancías; por tanto, actúa como dispositivo que maximiza la distribución y el consumo de bienes y servicios en las grandes ciudades.

La participación de agentes de distinta naturaleza coordinada a través de CC revela una de las tendencias actuales de las estrategias de integración del capital a partir de los esquemas de asociación entre empresas financieras, inmobiliarias y comerciales: mientras el capital financiero-inmobiliario requiere de empresas minoristas para captar rentas urbanas, el capital productivo-comercial necesita del centro comercial para garantizar sus rendimientos colocando grandes volúmenes de bienes y servicios en los mercados urbanos.

\section{Difusión espacial y nuevos subcentros urbanos}

La apertura de cc en distintos momentos permite identificar fases y tendencias que reflejan estrategias adaptativas a la dinámica socioespacial de la ciudad. Las estrategias de localización siguen, en principio, los patrones espaciales de expansión de la metrópoli registrados a lo largo de las últimas décadas. Ello se constata a partir de los años de apertura de los cc, pues entre 1969 y 2016 más del 60\% ocurrió en áreas suburbanas y periféricas de la metrópoli (tabla 3). Además de seguir la progresión de la mancha urbana, las tendencias que registran los Cc durante casi cinco décadas ilustran cómo dichos equipamientos se asociaron a los patrones de segmentación y fragmentación sociorresidencial de la ciudad. 
Una primera fase corresponde al proceso de introducción, que va de 1969 hasta mediados de los ochenta (figura 1). El crecimiento de los Cc en la Ciudad de México fue incipiente, pues por casi tres lustros su número llegó solo a diez unidades, lo que refleja un esquema de discreta penetración en las preferencias de consumidores. En este periodo los primeros CC formaron grandes equipamientos horizontales, ubicados en la mayoría de los casos sobre avenidas primarias que facilitaban la conectividad; contaban además con una amplia superficie de estacionamiento, que daba cierta exclusividad a sectores que disponían de automóvil. Estos CC se localizaron en demarcaciones suburbanas de la CDMX, así como en municipios periféricos del estado de México, en ambos casos ubicados en zonas residenciales de clase media y algunos enclaves de altos ingresos. Tal fue el caso de Plaza Universidad (1969), Plaza Satélite (1971), Valle Dorado (1979), Perisur (1981) y Centro Coyoacán (1982).

TABla 3 Zona Metropolitana de la Ciudad de México: centros comerciales edificados por periodos, de acuerdo con su localización, 1969-2016

\begin{tabular}{|c|c|c|c|c|c|c|}
\hline $\begin{array}{c}\text { SECTOR/DISTANCIA } \\
\text { RADIAL AL CENTRO DE } \\
\text { LA CIUDAD Y ENTRE } \\
\text { SECCIONES } \\
\end{array}$ & $\begin{array}{l}\text { I969- } \\
1984\end{array}$ & $\begin{array}{l}1985- \\
1999\end{array}$ & $\begin{array}{c}2000- \\
2016\end{array}$ & $\begin{array}{c}\text { NÚMERO } \\
\text { DE } \\
\text { UNIDADES }\end{array}$ & $\begin{array}{c}\text { PORCEN- } \\
\text { TAJE }\end{array}$ & EJEMPLOS \\
\hline $\begin{array}{l}\text { Centro histórico } \\
(0-2 \text { kilómetros })\end{array}$ & 0 & 0 & 1 & 1 & 0,5 & Parque Alameda. \\
\hline $\begin{array}{l}\text { Zona pericentral } \\
\text { (2-4 kilómetros) }\end{array}$ & 1 & 2 & 17 & 20 & 9,0 & $\begin{array}{l}\text { Forum Buenavista, Parque } \\
\text { Delta, Urban Center Condesa, } \\
\text { Torre Diana. }\end{array}$ \\
\hline $\begin{array}{l}\text { Zona suburbana } \\
\text { (4-8 kilómetros) }\end{array}$ & 4 & 19 & 35 & 58 & 26,2 & $\begin{array}{l}\text { Parque Tezontle, Oasis Coyoa- } \\
\text { cán, Antara Polanco. }\end{array}$ \\
\hline $\begin{array}{l}\text { Periferia urbana } \\
\text { (8-16 kilómetros) }\end{array}$ & 5 & 13 & 64 & 82 & 37,1 & $\begin{array}{l}\text { Espacio Interlomas, Plaza Bella } \\
\text { Mexiquense, Zentralia Coacal- } \\
\text { co, Patio Chimalhuacán. }\end{array}$ \\
\hline $\begin{array}{l}\text { Periferia metropolitana } \\
\text { (16-24 kilómetros) }\end{array}$ & 0 & 0 & 6 & 6 & 2,7 & $\begin{array}{l}\text { Town Center Zumpango, Plaza } \\
\text { Los Volcanes, Plaza Sendero } \\
\text { Ixtapaluca. }\end{array}$ \\
\hline CC año no especificado & 0 & 0 & 0 & 54 & 24,4 & \\
\hline Total & 10 & 34 & 123 & 221 & 100,0 & \\
\hline \multicolumn{7}{|l|}{ NOTA } \\
\hline $\begin{array}{ll}\text { FUENTE } & \text { ELABORACIÓN } \\
& \text { DE EMPRESAS }\end{array}$ & $\begin{array}{l}\text { PROPI } \\
\text { DESAR }\end{array}$ & $\begin{array}{l}\text { A PAR } \\
\text { LLAD }\end{array}$ & $\begin{array}{l}\text { IR DE } \\
\text { RAS }\end{array}$ & S.E MEDI & $\mathrm{DE} \mathrm{COM}$ & NICACIÓN (2OI 5) Y PÁGINAS WEB \\
\hline
\end{tabular}

Una segunda etapa, que va desde mediados de la década de los ochenta hasta finales de los noventa (figura 2), se caracteriza por una relativa expansión y diversificación. En este periodo los cc crecieron de manera importante en número: se tienen identificadas 34 nuevas unidades, considerando solo aquellas donde se cuenta con el registro del ańo de apertura. El rasgo más significativo en esta fase es que los CC iniciaron un proceso de diversificación de su oferta bajo esquemas que complementaron productos y servicios básicos con servicios especializados y amenidades. Así, los cc se transformaron en espacios con nuevas tiendas de marca globales, 
franquicias, almacenes especializados y sucursales de servicios bancarios y gubernamentales, entre otras. Ello implicó una transformación de las formas y opciones de consumo, el mejor ejemplo de lo cual quizá fueron las salas multicine, pues con el cambio de concepto, la transformación de empresas nacionales y el arribo de consorcios trasnacionales, este segmento del entretenimiento comenzó a desempeñar un papel estratégico en la captación de nuevos segmentos, lo cual en muchos casos posicionó estos emprendimientos como los nuevos negocios ancla de los CC.

FIGURA I | ZMVM: cC edificados de 1969 a 1984

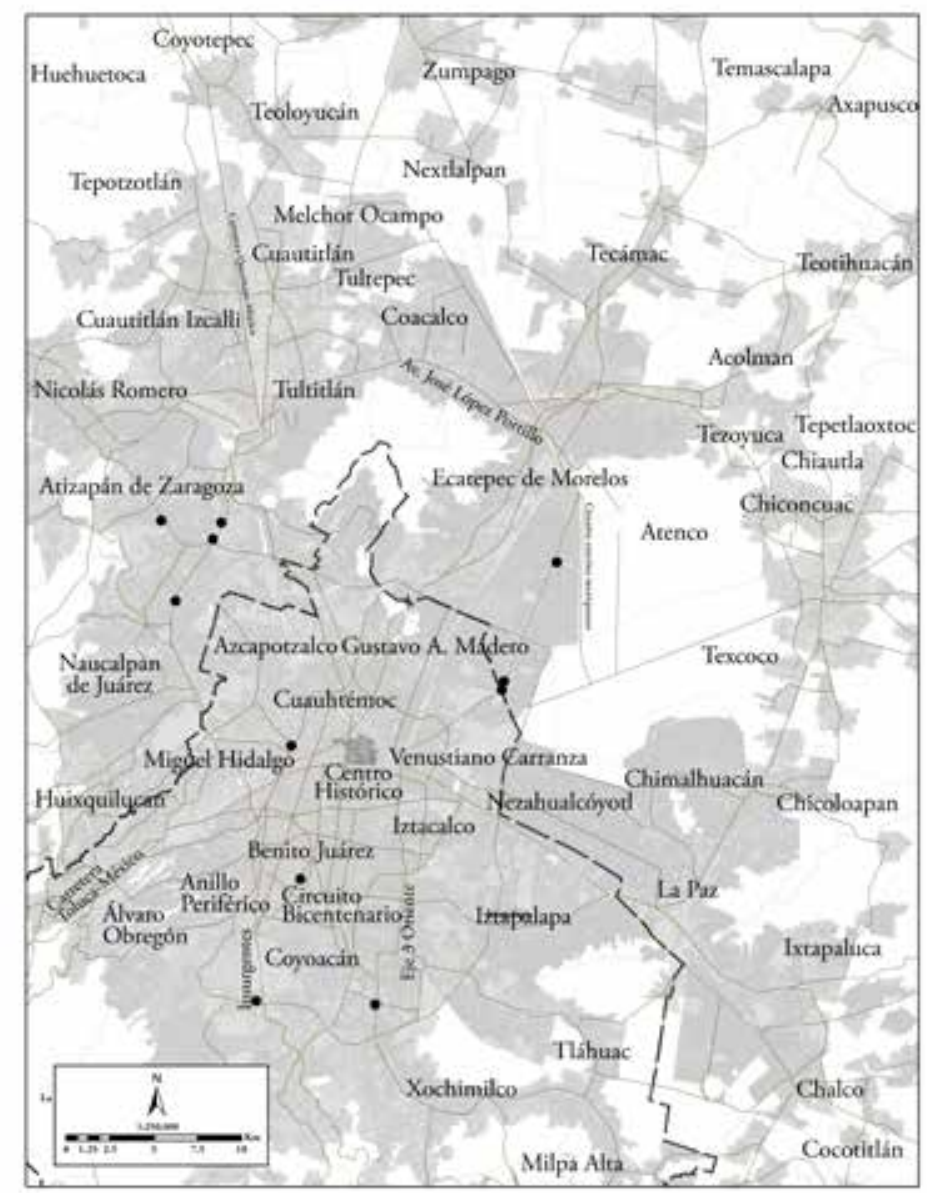


FIGURA 2 | ZMVM: cC edificados de 1985-2000

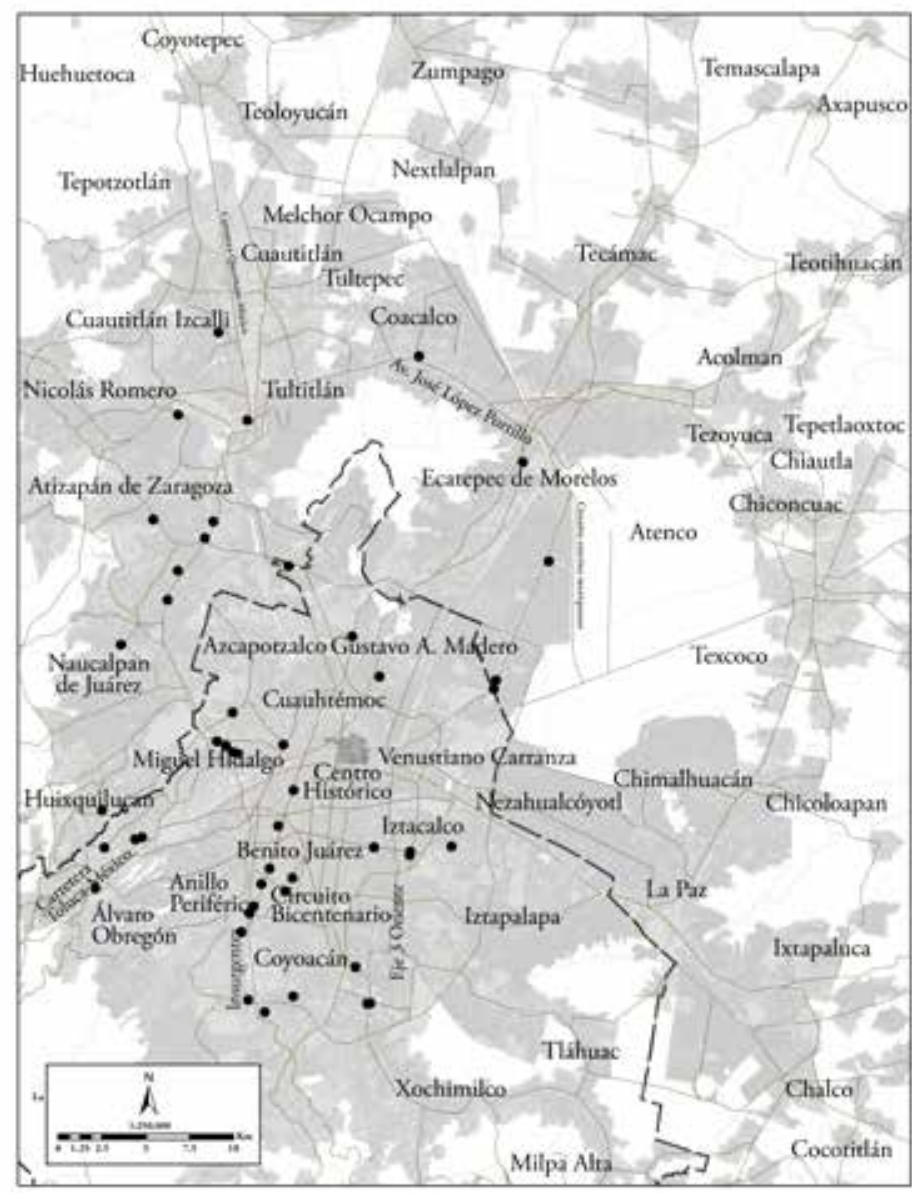

NOTA LA FIGURA 2 INCLUYE LOS CC DEL PERIODO ANTERIOR (I969-I84)

FUENTE ELABORACIÓN PROPIA A PARTIR DE M.S.E MEDIOS DE COMUNICACIÓN (2OI5) Y PÁGINAS WEB DE EMPRESAS DESARROLLADORAS 
FIGURA 3 | ZMVM: CC edificados de 1986-2016

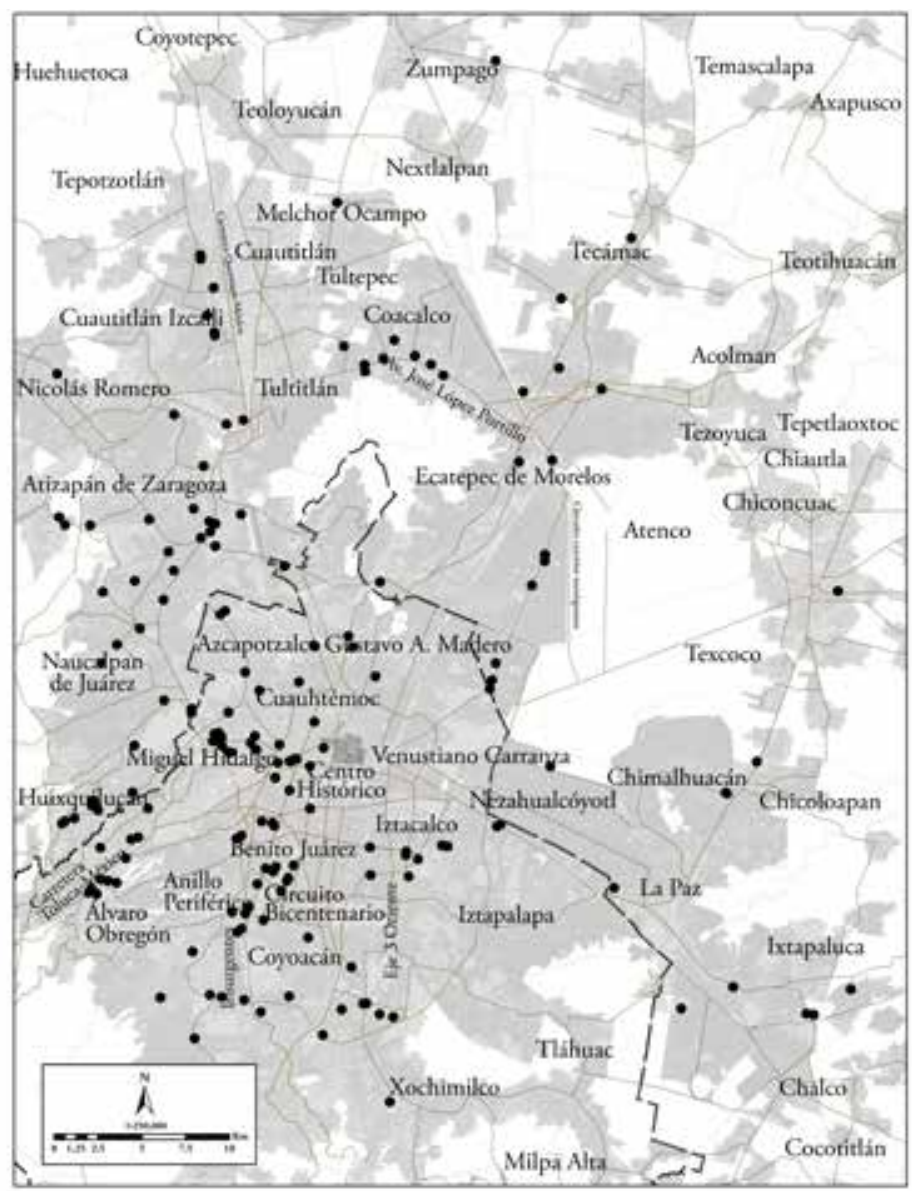

NOTA LA FIGURA 3 AGRUPA A TODAS LAS UNIDADES EDIFICADAS EN LOS DOS PERIODOS ANTERIORES MÁS LAS INTEGRADAS ENTRE I 986-20I6

FUENTE ELABORACIÓN PROPIA A PARTIR DE M.S.E MEdios DE COMUNICACIÓN (2015) y PÁGINAS WEB DE EMPRESAS DESARROLLADORAS

En esta etapa, la mayoría de los cc fueron edificados en contextos residenciales suburbanos consolidados y periurbanos de más reciente aparición. Entre ellos se encuentran Centro Santa Fe (1986), en el poniente de la metrópoli; los que se edificaron en áreas del norte de la ciudad en la delegación Gustavo A. Madero y el municipio de Ecatepec, como Plaza Lindavista (1990) y Vallejo 2000 (1994), así como Vía Morelos (1997). Además continuaron apareciendo en áreas de reciente urbanización, como en Cuautitlán Izcalli, Naucalpan y Tlalnepantla, donde se edificaron Multiplaza Izcalli (1989), Perinorte (1990), Centro Comercial Interlomas (1991), Multiplaza La Hacienda (1991) y Mundo E (1998). En el caso del sur de la ciudad, los CC registraron una relativa expansión en las delegaciones de Coyoacán y Tlalpan a partir de casos como Galerías Coapa (1992), Plaza Loreto (1994), 
Pabellón Altavista (1996) y Gran Sur (1999). Otros cc también se instalaron en zonas de negocios y corredores comerciales y financieros suburbanos y pericentrales de la ciudad, como Pabellón Polanco (1990), Galerías Insurgentes (1992) y Plaza Insurgentes (1996).

La tercera fase corresponde al momento de mayor colonización, innovación funcional y mutación morfológica, el cual se observa desde finales de los noventa, pero sobre todo en los primeros tres lustros del siglo XXI (figura 3). En esta etapa los CC no solo duplicaron su número entre el año 2000 y 2016, sino que adquirieron escalas flexibles y esquemas tematizados de consumo adaptados a distintos nichos de consumidores. Ello marcó distintas tendencias, como su transición hacia lugares con mayores funciones de ocio y entretenimiento; su inserción en edificios de usos mixtos; su flexibilidad en tamaño a partir de formatos atomizados (menores de 10 mil metros cuadrados) y de grandes dimensiones (cercanas o superiores a 100 mil metros cuadrados); su reestructuración morfológica de recintos cerrados y monolíticos hacia espacios en varios niveles y escenarios abiertos y semiabiertos que simulan calles comerciales; y finalmente, su mayor segmentación, que ha permitido consolidar esquemas orientados tanto a consumidores de elite en zonas privilegiadas, con ofertas de productos y servicios de exclusividad, como a sectores populares que ahora acceden a estos lugares, donde encuentran productos en formatos de tiendas de bajo costo y servicios genéricos.

El proceso de mayor expansión de cc, que se observa desde finales de los noventa a los primeros tres lustros del siglo XXI, presenta cuatro tendencias en sus patrones de difusión espacial.

En primer lugar, una localización acentuada hacia áreas periurbanas del norte en municipios del estado de México como Coacalco, Atizapán y Cuautitlán Izcalli, donde ha tenido lugar un importante auge de conjuntos residenciales para segmentos medios, así como densas unidades habitaciones de interés social.

Segundo, una producción importante de equipamientos en áreas pericentrales y suburbanas sujetas a procesos de reciclamiento urbano sobre enormes predios, como los registrados en los casos de Moliere Dos22 (2003), que se levantó donde se ubicaba un colegio de jesuitas; Parque Delta (2005), que ocupó el predio del antiguo parque de béisbol perteneciente al organismo federal de seguridad social (Instituto Mexicano del Seguro Social); Fórum Buenavista (2008), el cual se desarrolló sobre la desaparecida estación central de ferrocarriles de pasajeros de la ciudad; Plaza Ciudad Jardín, en una zona clausurada de confinamiento de residuos sólidos; Paseo Acoxpa (2010) lo hizo sobre los terrenos que dejó una antigua fábrica de hilados sintéticos; más recientemente, Centro Comercial Las Américas (2012) se edificó sobre los terrenos que ocupaba una empresa de productos químicos (Sosa Texcoco); Plaza Carso (2014) se instaló en la antigua zona industrial de la Ampliación Granada; Oasis Coyoacán (2015) se edificó sobre un predio anteriormente ocupado por una fábrica estadounidense de cosméticos; Parques Toreo Central (2015) se instaló en el antiguo centro de tauromaquia y espectáculos del Toreo de Cuatro Caminos; Pabellón Cuemanco (2015) se edificó sobre un extenso predio que dejó una empresa dedicada a la venta de muebles y electrodomésticos; finalmente, Parque Vía Vallejo (2016) ocupó el área que dejó el cierre de una fábrica de cartón. 
En tercer lugar, la localización de la mayoría de Cc sigue la lógica de agruparse sobre importantes áreas residenciales medias, con una mayor presencia en la parte poniente y sur de la metrópoli y sobre ejes urbanos comerciales y áreas terciarias. Así, podemos destacar su presencia en avenida Cuauhtémoc y su prolongación avenida Universidad; sobre Insurgentes en su segmento centro y sur; a lo largo de avenida Miramontes en la zona de Villa Coapa y en el segmento poniente del periférico. En el caso de áreas con una importante actividad terciaria, destacan Polanco, la zona de Santa Fe y Cuicuilco, lugares donde los Cc han tendido a integrarse en áreas financieras y complejos corporativos y de oficinas; mientras en el norte destaca la zona de Satélite en Naucalpan y el corredor de Periférico Norte y su prolongación Autopista México-Querétaro (Tlalnepantla y Cuautitlán), así como la vía José López-Portillo en su segmento Coacalco y Tultitlán (tabla 4).

Finalmente, se encuentran los CC de reciente aparición como enclaves aislados en los confines del norte y oriente de la metrópoli, en municipios mexiquenses como Ojo de Agua, Villa Nicolás Romero, Zumpango y Texcoco. En estas demarcaciones han proliferado recientemente desarrollos residenciales de nivel medio y condominios de interés social con una limitada oferta de equipamientos y servicios básicos, por lo cual un CC cercano resulta una opción para satisfacer en cierta medida su demanda. Cabe destacar la escasa presencia de CC en la porción oriente de la ZMVM. Siendo la zona con mayor población de la metrópoli y la que registra mayores sectores de bajos ingresos, los centros comerciales resultan excepcionales, algunos ubicados en la avenida Central en Ecatepec, otros en la zona circundante a la Central de Abastos en Iztapalapa y a lo largo de la avenida Ignacio Zaragoza; finalmente también aparecen aisladamente en municipios como Ixtapaluca y Chimalhuacán. En todos estos casos los cc se favorecen por su accesibilidad o bien por su proximidad a grandes conjuntos de vivienda de interés social (figura 4).

Bajo el fenómeno de dispersión espacial propio de metrópolis extendidas y de una enorme masa de consumidores, como ocurre en la ZMVM, los mayores CC también contribuyen a la configuración de una estructura policéntrica. Los cc de mayor demanda han logrado impulsar la formación de nuevas centralidades en la ciudad, pues su elevado aforo ha tenido un importante poder estructurante en la movilidad de personas, en la generación de circuitos económicos y en la articulación intraurbana de las redes de transporte. Esta funcionalidad es atribuible al menos a cinco CC que forman amplias áreas de servicio a partir de aforos cercanos o superiores a los 2 millones de usuarios mensuales: el Multiplaza Aragón, Plaza Satélite, Fórum Buenavista, el conjunto integrado por Plaza Oriente-Parque Tezontle y el Centro Comercial Perisur (tabla 5). En este grupo, el aforo promedio ronda entre las $60 \mathrm{mil}$ y 100 mil personas al día, cifra muy cercana a la registrada por el Aeropuerto Internacional de la Ciudad de México (AICM), pero inferior a la de Central de Abastos (CEDA), ambos reconocidos como importantes subcentros de la metrópoli. ${ }^{9}$

9 El AICM en el 2015 reportó un movimiento de pasajeros en sus dos terminales de 38,4 millones de personas al año, equivalentes a un promedio de 3,2 millones mensuales y poco más de 100 mil por día (AIMC, 2015). La CEDA reporta una afluencia promedio de 450 mil clientes y cerca de 75 mil empleados que ingresan diariamente a este complejo de distribución mayorista de alimentos (Central de Abastos de la Ciudad de México [Uneabasto], 2015). 
FIGURA 4 | ZMVM: cC edificados en 2016 y ubicación en los diferentes sectores

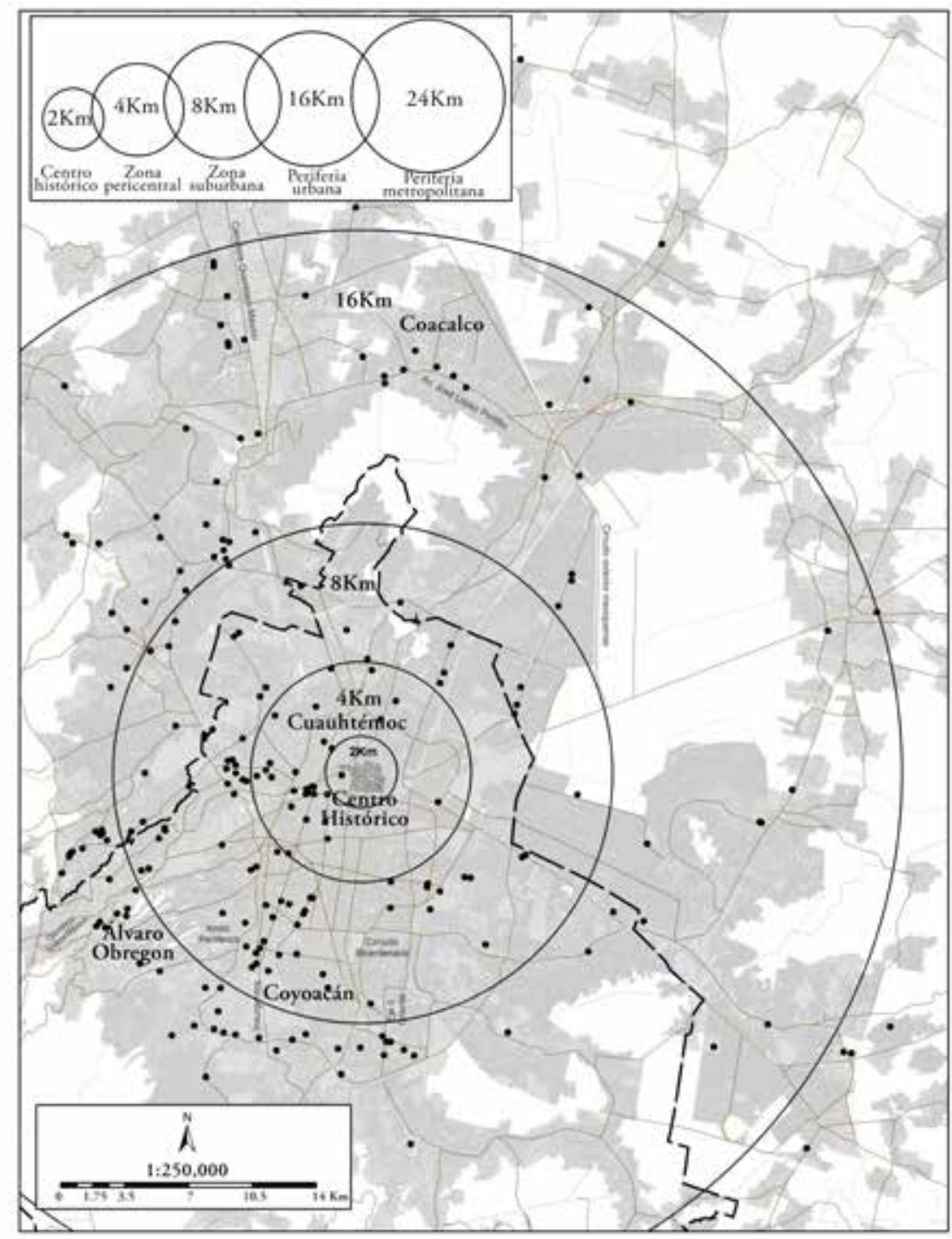

FUENTE ELABORACIÓN PROPIA A PARTIR DE M.S.E MEDIOS DE COMUNICACIÓN (2OI5) y PÁGINAS WEB DE EMPRESAS DESARROLLADORAS 
TABla 4 Zona Metropolitana del Valle de México: cc ubicados en complejos, corredores terciarios y desarrollos de usos mixtos

\begin{tabular}{|c|c|c|c|}
\hline MODALIDAD & UBICACIÓN & EJEMPLOS & NÚMERO \\
\hline \multirow{3}{*}{$\begin{array}{l}\text { Centros } \\
\text { comerciales } \\
\text { en áreas o } \\
\text { distritos } \\
\text { terciarios }\end{array}$} & Santa Fe & $\begin{array}{l}\text { Centro Comercial Santa Fe, Zentrika, City Walk, } \\
\text { Garden Santa Fe, Park Plaza Samara, Patio Santa Fe }\end{array}$ & 6 \\
\hline & Polanco & $\begin{array}{l}\text { Plaza Carso, Centro Comercial Polanco, Antara Polanco, } \\
\text { Parques Polanco, Punto Polanco }\end{array}$ & 6 \\
\hline & Tlalnepantla & $\begin{array}{l}\text { Fashion Mall Plaza Tlalne, Centro Olimpus, Multiplaza } \\
\text { Pirules, Multiplaza Arboledas, Multimart Baz, } \\
\text { Multiplaza Valle Dorado }\end{array}$ & 6 \\
\hline \multirow{8}{*}{$\begin{array}{l}\text { Ejes terciarios } \\
\text { con presencia } \\
\text { de centros } \\
\text { comerciales }\end{array}$} & $\begin{array}{l}\text { Avenidas Universi- } \\
\text { dad-Cuauhtémoc } \\
\text { (Sur-norte) }\end{array}$ & $\begin{array}{l}\text { Oasis Coyoacán, Centro Coyoacán, Patio Universidad, } \\
\text { Plaza Universidad, Pabellón del Valle, Universidad 767, } \\
\text { Parque Delta, Pabellón Cuauhtémoc }\end{array}$ & 8 \\
\hline & $\begin{array}{l}\text { Avenida Miramontes } \\
\text { y áreas contiguas }\end{array}$ & $\begin{array}{l}\text { Coaplaza, Galerías Coapa, Plaza Fiesta Coapa, } \\
\text { Plaza Soriana Miramontes, Superplaza Miramontes, } \\
\text { Paseo Acoxpa, Plaza América }\end{array}$ & 7 \\
\hline & $\begin{array}{l}\text { Avenida Insurgentes } \\
\text { (Centro-sur) }\end{array}$ & $\begin{array}{l}\text { Plaza Niza66, Plaza Insurgentes, Galerías Insurgentes, } \\
\text { Centro Insurgentes, Plaza Inn, Perisur, Plaza Inbursa } \\
\text { Cuicuilco }\end{array}$ & 7 \\
\hline & Avenida Revolución & $\begin{array}{l}\text { Pabellón Altavista, Grand San Ángel, Patio Revolución, } \\
\text { Plaza Loreto }\end{array}$ & 4 \\
\hline & $\begin{array}{l}\text { Anillo periférico } \\
\text { segmento Sur- } \\
\text { poniente }\end{array}$ & $\begin{array}{l}\text { Patio Pedregal, Acora Pedregal, Terraza Pedregal, Plaza } \\
\text { Santa Teresa, Centro Comercial San Jerónimo, Perisur }\end{array}$ & 6 \\
\hline & $\begin{array}{l}\text { Anillo periférico } \\
\text { segmento Nor- } \\
\text { poniente y su pro- } \\
\text { longación Autopista } \\
\text { México-Querétaro }\end{array}$ & $\begin{array}{l}\text { Perinorte, Toreo, Parques Toreo Lomas Plaza, Diamante, } \\
\text { Pabellón Las Torres, Plaza Satélite, Mundo E, Multiplaza } \\
\text { Pirules, Multiplaza Arboledas, Multiplaza Valle Dorado, } \\
\text { Centro Comercial Cuautitlán-Periférico }\end{array}$ & 12 \\
\hline & $\begin{array}{l}\text { Vía José López } \\
\text { Portillo }\end{array}$ & $\begin{array}{l}\text { Cosmopol, Coacalco Power Center, Paseo Coacalco, } \\
\text { Plaza Las Flores, Zentralia Coacalco, Plaza Coacalco }\end{array}$ & 6 \\
\hline & $\begin{array}{l}\text { Avenida Central } \\
\text { (Carlos Hank } \\
\text { González) }\end{array}$ & $\begin{array}{l}\text { Multiplaza Bosques, Multiplaza San Juan, Multiplaza } \\
\text { Vergel, Center Plazas Ecatepec, Multiplaza Aragón, } \\
\text { Mexipuerto Ciudad Azteca }\end{array}$ & 6 \\
\hline \multirow{4}{*}{$\begin{array}{l}\text { Centros } \\
\text { comerciales } \\
\text { en desarrollos } \\
\text { de usos } \\
\text { mixtos }\end{array}$} & Insurgentes & $\begin{array}{l}\text { Plaza Inn, Centro Insurgentes, Forum Buenavista, } \\
\text { Plaza Inbursa Cuicuilco }\end{array}$ & 4 \\
\hline & Paseo de la Reforma & $\begin{array}{l}\text { Torre Virreyes, Torre Diana, Reforma 180, } \\
\text { Torre Reforma Latino, Capital Reforma, Reforma } 222\end{array}$ & 6 \\
\hline & Polanco & $\begin{array}{l}\text { Parques Polanco, Moliere Dos22, Punto Polanco, } \\
\text { Plaza Carso }\end{array}$ & 4 \\
\hline & Otros & $\begin{array}{l}\text { Parques Toreo Central, Patio Universidad, Metrópoli } \\
\text { Patriotismo, Park Plaza Samara, Arcos Bosque II }\end{array}$ & 5 \\
\hline
\end{tabular}

FUENTE ELABORACIÓN PROPIA A PARTIR DE M.S.E MEDIOS DE COMUNICACIÓN (2OI5) Y PÁGINAS WEB DE EMPRESAS DESARROLLADORAS 
Tabla 5 | Zona Metropolitana del Valle de México: Top 20 de los centros comerciales de acuerdo con el aforo promedio mensual

\begin{tabular}{|c|c|c|c|c|}
\hline & CENTRO COMERCIAL & $\begin{array}{c}\text { SUPERFICIE } \\
\text { RENTABLE }\left(\mathbf{M}^{2}\right)\end{array}$ & $\begin{array}{l}\text { NÚMERO DE } \\
\text { TIENDAS }\end{array}$ & $\begin{array}{c}\text { AFLUENCIA MENSUAL } \\
\text { PROMEDIO (MILLONES } \\
\text { DE VISITANTES) }\end{array}$ \\
\hline 1 & Multiplaza Aragón & 138.304 & 390 & 3,00 \\
\hline 2 & Plaza Satélite & 133.670 & 182 & 2,40 \\
\hline 3 & Fórum Buenavista & 90.465 & 262 & 1,90 \\
\hline 4 & $\begin{array}{l}\text { Centro Comercial Plaza } \\
\text { Oriente+Parque Tezontle }\end{array}$ & 210.000 & 360 & 1,81 \\
\hline 5 & Centro Comercial Perisur & 270.000 & 270 & 1,80 \\
\hline 6 & Parque Delta & 70.224 & 120 & 1,50 \\
\hline 7 & Centro Comercial Santa Fe & 128.367 & 434 & 1,50 \\
\hline 8 & Galerías Coapa & 58.700 & 156 & 1,50 \\
\hline 9 & Centro Comercial San Jerónimo & n.d. & 170 & 1,50 \\
\hline 6 & Mundo E & 128.734 & 270 & 1,60 \\
\hline 11 & Centro Coyoacán & 28.000 & 150 & 1,20 \\
\hline 12 & Plaza Universidad & 30.569 & 85 & 1,10 \\
\hline 13 & Plaza Las Américas & 180.400 & 250 & 1,00 \\
\hline 14 & Parque Lindavista & 68.692 & 187 & 0,87 \\
\hline 15 & Coacalco Power Center & 58.000 & 156 & 0,80 \\
\hline 16 & Pabellón Cuauhtémoc & 45.400 & 98 & 0,80 \\
\hline 17 & Galerías Plaza de las Estrellas & 36.000 & 215 & 0,80 \\
\hline 18 & Plaza Inn & 19.800 & 230 & 0,80 \\
\hline 19 & Centro Comercial Gran Sur & 70.000 & 120 & 0,75 \\
\hline 20 & Galerías Insurgentes & 60.000 & 122 & 0,75 \\
\hline
\end{tabular}

FUENTE ELABORACIÓN PROPIA A M.S.E MEDIOS DE COMUNICACIÓN (2OI5) Y PÁGINAS WEB DE EMPRESAS DESARROLLADORAS

Estas subcentralidades generadas por Cc han impuesto una nueva dinámica a sus entornos territoriales, producto de la revaloración y especulación del suelo, que han incrementado las rentas de manera extraordinaria. Esto significa que los Cc tienen un efecto expansor y regenerador por la atracción de nuevas empresas y actividades que promueven la sucesión y recalificación de usos del suelo, donde nuevos negocios aprovechan la centralidad y las economías de aglomeración generadas. Esto, al final del día, también contribuye tanto a una mayor densificación y consolidación de áreas y enclaves terciarios, como al despliegue de nuevos negocios inmobiliarios residenciales que se vuelven atractivos y rentables para sectores de ingresos medios o de elite, lo cual retroalimenta el proceso de segregación urbana que caracteriza la ciudad.

Las tendencias mencionadas se distinguen en varios centros comerciales. Por ejemplo, el Centro Comercial Santa Fe, de ser originalmente un equipamiento comercial periférico en el poniente de la metrópoli, se ha convertido en el principal distrito de corporativos nacionales y globales de la ciudad; a la vez, se ha consolidado como un nodo de educación superior, así como un espacio para una amplia producción inmobiliaria de residencias destinadas a segmentos de altos ingresos. 
Este lugar puede ser considerado uno de los subcentros de mayor complejidad de la metrópoli, por los importantes flujos de empleados, residentes y consumidores que se articulan en el área.

Plaza Universidad ha tenido también un importante efecto transformador de un corredor terciario donde se combinan segmentos comerciales, servicios especializados, corporativos, entre otros. A lo largo de este eje y su área adyacente se instalaron, en el transcurso de cuatro décadas, un corporativo bancario, otros cuatro centros comerciales, tres hipermercados y un club de precios, varias empresas concesionarias automotrices, un complejo cinematográfico y dos estaciones radiofónicas, así como un hospital privado de especialidades. Todos estos proyectos se acompañan con un frente de expansión inmobiliario de residencias medias que ha venido desplazando a los habitantes del pueblo tradicional de Xoco, ubicado en el entorno de todos estos desarrollos de actividad terciaria.

Otro caso emblemático es Fórum Buenavista. Al formar el proyecto que permitió desmantelar la antigua estación de ferrocarriles de pasajeros de la capital, se originó uno de los CC de más grandes dimensiones, actualmente integrado a una intervención urbana estratégica de movilidad que conjuga el tren suburbano, dos líneas del metrobús y un centro de transferencia multimodal de transporte, lo que permite generar uno de los aforos potenciales más altos que confluyen en el nodo comercial. Forum Buenavista es un caso excepcional, debido a que su presencia ha implicado una importante reactivación terciaria y especulación de vivienda de una porción de las áreas centrales de la ciudad, que comienzan a registrar una paulatina ascendencia sociorresidencial a partir de la edificación de condominios para sectores medios, particularmente en las zonas adyacentes ocupadas por los barrios populares de Santa María la Rivera y la colonia Guerrero, lo cual denota, como en el caso anterior, efectos de gentrificación progresiva.

\section{Conclusiones}

Los cc son expresiones de la cultura contemporánea del consumo en las grandes ciudades y metrópolis, y como tales cumplen una función estratégica para concentrar, acelerar y maximizar la circulación de bienes y servicios. Como negocios inmobiliarios, constituyen uno de los medios más eficientes para captar grandes volúmenes de rentas; por esta razón, se han convertido, en países como México, en uno de los segmentos del mercado de bienes raíces más dinámicos en las últimas décadas. La difusión de distintas modalidades y tamaños de $\mathrm{CC}$ ha promovido variadas sinergias entre el capital financiero, inmobiliario y comercial a través de complejas fórmulas de participación y coalición de agentes financieros globales, empresas desarrolladoras y operadoras inmobiliarias, así como grandes cadenas de retailers, las cuales conjugan fuentes diversificadas de inversión directa y bursátil que han permitido apuntalar este sector.

El ascenso de los CC como negocios inmobiliarios en la ciudad contemporánea ha promovido diversas transformaciones del espacio urbano. Como medios de revalorización y rentabilización del suelo, acompañan los procesos de expansión urbana residencial y participan en los procesos de regeneración de antiguas áreas y 
de sectores en declive; también forman parte de las grandes intervenciones urbanas, en las cuales contribuyen a consolidar corredores comerciales, distritos de negocios, áreas terciarias y complejos de usos mixtos. Su papel en la formación de economías de aglomeración ayuda impulsar la creación de nuevas subcentralidades, proceso que tiene lugar a partir de la atracción de numerosas empresas y la articulación de importantes flujos de consumidores y usuarios.

En la Ciudad de México, los Cc han tendido hacia una transformación de su morfología, tamańos y funciones que obedece a una readaptación permanente a nuevos estratos sociales, entornos de consumidores y estilos de vida, lo cual permite configurar espacios donde se diversifican y tematizan las prácticas de consumo. Sin embargo, las características de difusión espacial de CC hacia zonas consolidadas y periféricas de la Ciudad con mayores niveles de ingresos denota una tendencia dominante, caracterizada por localizaciones selectivas que se ajustan a las áreas de mayor calidad de vida, lo que a la vez contribuye a consolidar la segmentación y la fragmentación sociorresidencial que caracterizan la ciudad.

\section{Referencias bibliográficas}

Amaya, C.A. (2009). Rol de los centros comerciales en la organización espacial de las principales aglomeraciones urbanas de Venezuela. Revista Geográfica Venezolana, 50(2), 263-286. https://dialnet.unirioja.es/servlet/articulo?codigo $=3398498$

Bauman, Z. (2007). Vida de consumo. México, D.F.: Fondo de Cultura Económica.

Caprón, G. \& Sabatier, B. (2007). Identidades urbanas y culturas públicas en la globalización. Centros comerciales paisajísticos en Río de Janeiro y México. Alteridades, 17(33), 8797. http://www.redalyc.org/articulo.oa?id=74712772008

Cornejo, I. (2007). El lugar de los encuentros: comunicación y cultura en un centro comercial. México, D.F.: Universidad Iberoamericana.

Dávila, A. (2016). El mall: The spatial and class politics of shopping malls in Latin America. Berkeley, Ca: University of California Press.

De Mattos, C. (2008). Globalización, negocios inmobiliarios y transformación urbana. Nueva Sociedad, (212), 82-96. http://nuso.org/articulo/globalizacion-negocios-inmobiliariosy-transformacion-urbana/

De Simone, L. (2015). MetaMall. Espacio urbano y consumo en la ciudad neoliberal chilena. Santiago, Chile: Ril Editores-Pontificia Universidad Católica de Chile.

Escudero, L. (2008). Los centros comerciales. Espacios postmodernos de ocio y consumo. Cuenca: Ediciones de la Universidad de Castilla-La Mancha.

Lash, S. \& Urry, J. Economias de signos y espacio. Buenos Aires: Amorrortu editores.

Lizán, J. (2014). Los centros comerciales y su futuro 'promisorio'. Obras web/Inmobiliario. http://www.obrasweb.mx/inmobiliario/2014/10/09/la-evolucion-de-los-centroscomerciales-y-su-futuro-promisorio.

López, L. (1999). Centros comerciales: espacios que navegan entre la realidad y la ficción. México, D.F.: Nuestro Tiempo. 
López, L. (2006). Centros comerciales, recintos fortificados. Veredas, 7(12), 147-163. http:// bidi.xoc.uam.mx/tabla_contenido_fasciculo.php?id_fasciculo=268

Medina, F. (1997). El centro comercial: una "burbuja de cristal". Estudios sobre las Culturas Contemporáneas, 4(8), 61-91. http://bvirtual.ucol.mx/descargables/771_el_centro_ comercial.pdf

Molinillo, S. (2002). Centros comerciales de área urbana: Madrid: EsIC Editorial.

Monnet, J. (1996). Espacio público, comercio y urbanidad en Francia, México y Estados Unidos. Alteridades, 6(11), 11-25. http://alteridades.izt.uam.mx/index.php/Alte/ article/viewFile/550/548

Paquette, C. (2007). Comercio y planificación urbana: las nuevas grandes centralidades comerciales en los planes de desarrollo urbano de la Ciudad de México. Trace (Travaux et Recherches dans les Amériques du Centre), (51), 44-55. https://trace.revues.org/641

Pintaudi, S. \& Frúgol, H. (1992). Shopping centers. Espaço, cultura e modernidade nas cidades brasileiras. São Paulo: Editora Universidad Estadual Paulista (eusp).

Pradilla, E., Márquez, L., Carreón, S. \& Fonseca, C. (2008). Centros comerciales, terciarización y privatización de lo público. Ciudades, (79), 44-53. http://bit.ly/2lT82tA

Ritzer, G. (2006). La globalización de la nada. Madrid: Editorial Popular.

Salcedo-Hansen, R. (2003). Lo local, lo global y el mall: la lógica de la exclusión y la interdependencia. Revista de Geografia Norte Grande, (30), 103-115. http://www. redalyc.org/articulo.oa?id=30003009

Valenzuela, A. (2013). Dispositivos de la globalización: la construcción de grandes proyectos urbanos en Ciudad de México, EURE, 39(11), 101-118. https://doi.org/10.4067/ S0250-71612013000100004

Vázquez, Y. (2007). México y Puebla: del centro comercial a la ciudad. La construcción de nuevos territorios urbanos. Trace, (51), 56-70. http://www.redalyc.org/articulo. oa?id=423839507005

Vecslir, L. \& Cicolella, P. (2011). Relocalización de las actividades terciarias y cambios en la centralidad en la Región Metropolitana de Buenos Aires. Revista de Geografía Norte Grande, (49), 63-78. https://doi.org/10.4067/S0718-34022011000200005

\section{Documentos oficiales}

Aeropuerto Internacional de la Ciudad de México (AIMC). (2015). Estadísticas del Aeropuerto Internacional de la Ciudad de México. Secretaría de Comunicaciones y Transportes. http://www.aicm.com.mx/acercadelaicm/archivos/files/Estadisticas/ Estadisticas2015.pdf

Asociación Mexicana de Capital Privado (Amexcap). (2014). Fondos Inmobiliarios y de Infraestructura en México. https://amexcap.com/contenido/resultados-de-la-encuesta2014-sobre-inversion-de-fondos-inmobiliarios-y-de-infraestructura-en-mexico

Central de Abastos de la Ciudad de México (Uneabasto). (2015). Indicadores básicos de la Central de Abastos. http://www.uneabasto.com/cat.pdf

Consejo Nacional de Población (Conapo), Secretaría de Desarrollo Social (Sedesol), Secretaría de Gobernación (Segob). (2012). Catálogo sistema urbano nacional, México. Ciudad de México: Conapo-Sedesol-Segob. http://www.conapo.gob.mx/en/CONAPO/ Catalogo_Sistema_Urbano_Nacional_2012 
Cushman \& Wakefield (2014). Global Shopping Center Development Report. Nueva York: A Cushman \& Wakefield Research Publication.

Cushman \& Wakefield (2015). Main streets across the world. Nueva York: A Cushman \& Wakefield Research Publication. http://www.cushmanwakefield.com/en/researchand-insight/2016/main-streets-across-the-world-2016-2017/

International Council of Shopping Centers (ICSc). (2014). Shopping Centers: America's First and Foremost Marketplace. Nueva York: International Council of Shopping Centers. https://www.icsc.org/uploads/research/general/America-Marketplace.pdf

International Council of Shopping Centers (ICSC). (2015). Reporte 2015 de la industria de centros comerciales en América Latina. México: International Council of Shopping Centers. http://www.icsc.org/latam/uploads/RLA_White_Paper.pdf

M.S.E. Medios de Comunicación. (2015). Directorio de centros comerciales Distrito Federal y Estado de México. Ciudad de México: Plazas Comerciales Passion for Shopping. [Base de datos no pública].

\section{Páginas web consultadas:}

E-Group: http://www.e-group.com.mx

El Palacio de Hierro: http://www.elpalaciodehierro.com

El Puerto de Liverpool: http://www.liverpool.com.mx

Fibra Danhos: http://www.fibradanhos.com.mx/

Fibra Shop: http://www.fibrashop.mx/

Fibra Uno: http://fibra-uno.com/

GICSA: http://www.gicsa.com.mx

Grupo ACBC: http://www.grupoacbc.com

Grupo ACCION: http://www.accion.com.mx

Grupo Acosta Verde: http://www.grupoav.com

Grupo CAABSA: http://www.grupocaabsa.com/

Grupo Frisa: http://www.grupofrisa.com/

Grupo GDI Comercial: http://www.gdicomercial.com/

Grupo Sordo Madaleno Arquitectos: http://www.sordomadaleno.com/es/

ICON Group: http://icongroup.com.mx/

ICSC International Council of Shopping Centers: https://www.icsc.org/

Inmuebles Carso: http://www.incarso.com/

Malls México: http://www.mallsmexico.com

México Retail Properties: http://www.mrp.com.mx/

Plani Grupo: http://www.planigrupo.com/

Sears Operadora México: http://www.sears.com.mx/

zKC Fondo Inmobiliario: http://www.zkc.com.mx 